\title{
Statistical Quality Control on the Mechanical Properties on Resultant Pellets of Itakpe And Agbaja Iron Ore Blends
}

\author{
C.N Mbah ${ }^{1}$, Ocheri $\mathrm{C}^{2 *}$, Ubah J.C ${ }^{3}$, Alabi O.O ${ }^{3}$ \\ ${ }^{1}$ Dept. of Metallurgical and Materials Engineering, Enugu State University of Science and Technology \\ ${ }^{2}$ Dept. of Metallurgical and Materials Engineering, University of Nigeria, Nsukka \\ ${ }^{3}$ Dept of Computer Science, ICT University, Yaoundé, Cameroon \\ ${ }^{3}$ Dept. of Metallurgical and Materials Engineering, Federal University of Technology, \\ Akure
}

*Corresponding Authors: Ocheri C, Dept. of Metallurgical and Materials Engineering, University of Nigeria, Nsukka

\begin{abstract}
Statistical Quality Control (SQC) analysis deals with quantitative data; it is also a scientific method of analyzing masses of numerical data so as to summarize the essential features and relationship of data in order to generalize from the analysis pattern behaviour, for a particular outcome or future tendencies. This research work focused on the use of statistical quality control to verify the data generated when the produced pellets from Itakpe and Agbaja iron ores are blends. The values were tested using available equipment and machineries to determine the mechanical Properties of the pellets with a view to confirming the values as regards to international standards.The produced pellet samples and data collected for critical characteristics were determined to ascertain if they shifted away from the purely random pattern. One thousand six hundred samples were prepared and eight samples each were used for the various tests that are applicable to the mechanical properties of the pellets while the best six (6) values were taken. The average values and the range of the values were determined and also the standard deviation values as are indicated in all the tables. The range interval of the iron ore blends are performed were put at 5. .For each sample, twenty one test testes were carried out and value generated were used for the analyses. The obtained data generated were use to plot two control charts. The two control charts are ( $\overline{\mathbf{X}}$ and $\overline{\mathbf{R}}$ ) which were used to determine the performance and to indicate if the parameters generated remained in control and where there are variations, these will serve as early warning system for the information of the production of pellets from Itakpe and Agbaja iron ore.
\end{abstract}

Keywords: Statistical, Quality, Control, Pellets, Iron ores Sporadic, Non-random and Performance

\section{INTRODUCTION}

Iron ore deposit was discovered in Nigeria as far back as 1904 since then several Deposits have been discovered. The deposits are hematite, magnetite, goethite or siderite - goethite grades. The reserve is estimated at over 3 billion metric tons and their utilization deposits in iron and steel plants will reduce the cost of importation thereby saving foreign exchange, improve Nigerian's technology transfer i.e. agriculture, military defense and provide employment and revenue generation [1]

Statistical quality control method is based on the control of variability of process variable, consideration of the mechanical properties of the produced pellets as process variable, samples of mechanical properties measured the values which are randomly selected .The mechanical properties are critical parameters to be look out for when determining good and quality pellets as this translate to production of quality pellets with a view to producing liquid steel through the usage of the production furnaces like the blast furnace and the Direct Reduced Iron.The mechanical properties of the pellets investigated the following properties : Drop Number, Drop Resistance, Green Compressive Test, Dry Compressive Test, Indurating index value, Moisture content, tumbler index value, Abrasive index value and Micro porosity index .

\section{MATERials}

The Itakpe Iron ore is known of the topography it has which is of the region is a plateau rising gently to the north - east of Okene in the eastern part of Kogi State, down to the river Niger. The plateau is 
bestrewn with scattered hills which are made of Precambrian gneisses and granites that overlook the surrounding by about $200 \mathrm{~m}$ to $300 \mathrm{~m}$. [1]. The Itakpe iron ore deposits is part of these hills. Its estimated reserve is over 300 million tons while its proven reserve is 200 million tons [1].The deposit has an average iron ore content of $36 \%$. This has to be beneficiated at rate of 8 million tons per year to produce $64 \% \mathrm{Fe}$ concentrate as sinter materials, for the Ajaokuta Steel Company Limited Blast furnace and 60\% Fe concentrate as pellet feed for the Direct Reduction Plant (DRP) at the Delta Steel Company Limited, Aldaja, and Delta State. The iron ore is suitable as a feedstock to one of the Direct Reduction Methods of Iron making. The ore is typical of one formed by magnetic segregation. This iron ore deposit is the most elaborately investigated ferrous deposit in Nigeria, which is being developed for the utilization in the blast furnace. The picture below shows the sample of the Itakpe Iron ore sourced at the National Iron Ore Mining Company ( NIOMCO) Itakpe, Kogi State , Nigeria .The Itakpe iron ore specimen is known to be a compacted, crystalline like banded iron ore which has various colours like dark grey, brown and black. The Itakpe iron ore slightly magnetic in nature

The Agbaja Iron Ore is an acidic pisolitic/ oolitic ore consisting of goethite, magnetic and major amounts of aluminious and siliceous materials [2]. It cannot be used directly in the Blast Furnace process or other reduction process without further treatment e.g. palletization or briquetting. The ore is a lean ore and sedimentary origin [2]. It is therefore necessary to harness the opportunities created to work upon the ore in order to add economic value to our national economy. The ore is also known to be oolittitic in nature, limonite which occur in mannmilated or stalactite forms having fibrous structure resembling hematite [2]. The Agbaja Iron ore are made of brown compacted fine grained materials which consist of extremely lager particles which show the tendency to be friable. Agbaja iron ore is strongly magnetic [3]. The ore particles were further processed by crushing them for specific experimental procedure. The Agbaja iron ore sample is compacted ground fine particles which significantly exhibits the characteristics of being friable and also magnetically strong. The picture below shows the iron ore as being sourced at the Agbaja plateau in Kogi State. The aims and objective of blending these ores is to produce pellets that could be used in the production of molten iron using the Blast Furnace and the Direct Reduced Iron processes. It is also known that the Itakpe Iron ores are of more quality in high Fe concentrate than the Agbaja iron ore.

\section{Sample Preparation (Pellet Preparation)}

$15 \mathrm{~kg}$ of each iron ore of Itakpe and Agbaja were charged at different times into ball milling machine made by Bico Sprecher and Schn (2287) Industrial control, United State of America. Then one Thousand six hundred balls of varying diameters ranging from $15 \mathrm{~mm}$ to $40 \mathrm{~mm}$ were charged into the ball mill ( $15 \mathrm{~mm}$ balls -320 pieces, $20 \mathrm{~mm}$ balls- 320 pieces, $25 \mathrm{~mm}$ balls -320 pieces, $30 \mathrm{~mm}$ balls -320 pieces and $40 \mathrm{~mm}-320$ pieces).

The samples were allowed to mill for six (6) hours after which they were discharged and sieved using $0.63 \mathrm{~mm}$ sieve size. The oversize materials were recycled until they all passed through the $0.63 \mathrm{~mm}$ sieve. At this point, the samples prepared were worked upon:

$1.15 \mathrm{~kg}$ Itakpe iron ore pulverized to $-0.63 \mathrm{~mm}$ sieve size

2. $15 \mathrm{~kg}$ Agbaja iron ore pulverized to $-0.63 \mathrm{~mm}$ sieve size. [4]

$1500 \mathrm{~g}$ blended Iron ore was weighed with Itakpe iron ore in the blend-1425g. (95\%) and Agbaja iron ore in the blend-75g.(5\%) were weighed using Salter Digital weighing balance with trade mark Mettler Pm 2000.The weighed samples were charged into a clean and moisture free Erich 2287 Palletizing disc machine of $35 \mathrm{~cm}$ diameter wide palletizing disc. $4 \%$ lime was also added, while the Machine rotated at the speed of $25 \mathrm{rpm}$. The samples were properly mixed after which $1000 \mathrm{mls}$ of water by volume was measured and added to the iron ore mix in the rotating pelletizing disc which work gradually; while the charge were been scrapped on a continuous basis to avoid sticking to the disc. As the experiment progresses the pellets of varying diameters ranging from $10 \mathrm{~mm}$ to $20 \mathrm{~mm}$ were formed. Rotation of the Pelletizing disc continued in a reduced speed of 15rpm; after satisfactory formation of pellets impacted further strength on the pellets formed.

\subsection{Drop Number Test of Pellets from Height of $60 \mathrm{~cm}$}

The process of drop number test of pellets were performed by selecting eight (8) green pellets randomly from each group of blends produced. The selected eight (8) samples from each of the group were dropped from a measured height of $60 \mathrm{~cm}$ where the results of the number of drop numbers were 
observed until the samples fell and fractured into pieces. The number of failure progressed continuously until fracture were attained and the obtained results values were recorded as the drop number. The process were performed for other selected pellet samples where the average values of the best six(6) pellets sample results were taken and recorded as the drop number for that particular set of blend.

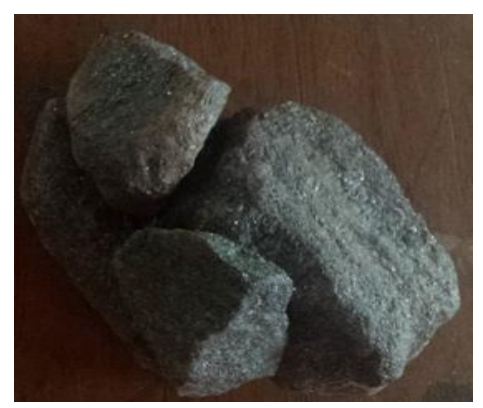

Figure3.1. the Itakpe Iron Ore

\subsection{Drop Resistance test of pellets from $48 \mathrm{~cm}, 60 \mathrm{~cm}$ and $72 \mathrm{~cm}$ height}

The drop resistance test of the pellets from $48 \mathrm{~cm}, 60 \mathrm{~cm}$ and $72 \mathrm{~cm}$ height were performed. Eight (8) green pellets samples from each group of blends produced were selected randomly. Eight samples were dropped for the drop resistance test as measured from a measured height of $48 \mathrm{~cm}, 60 \mathrm{~cm}$ and $72 \mathrm{~cm}$. Efforts were made to see that the number of drop resistance continued until the samples fell and fractured into pieces. The number of failures were observed until the samples were fractured into piece and thereafter the drop resistance values obtained were recorded after the samples were placed under load on the testing machine Note that all the eight $(8)$ selected samples were tested but the best six(6) samples test for the drop resistance results were taken. Average values of the drop resistance test of the samples reading gave the actual drop resistance test of the pellets.

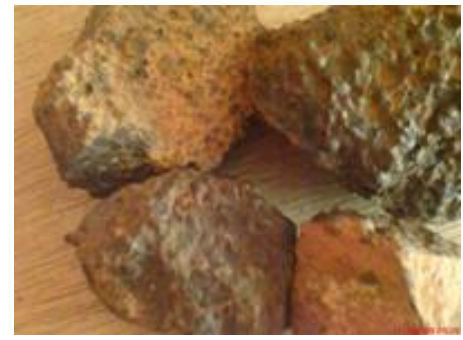

Figure3.2. the Agbaja Iron Ore

\subsection{Green Compressive Strength Test}

The Testometric testing Machine with M500-25CT a Laboratory Test equipment British model located at the Nigerian Liquefied Natural Gas (NLNG), at the Department of Metallurgical and Materials Engineering, University of Nigeria, Nsukka was used to perform the Green Compressive Strength test. Eight (8) samples were randomly selected from each group of the produced pellets which were subjected to load until scattered occurred. The readings of the scattered load were observed as the samples were placed under the testing machine. The results of the best six pellets samples were taken and recorded and the average value of the readings taken gave actual green compressive strength results. Same experimental procedures were repeated for the rest of the pellets.

\subsection{Dry Compressive Strength Test}

The dry compressive strength tests were carried out after the samples were randomly selected from each of the group of blend sample prepared this indicates that 95\% Itakpe iron ore and 5\% Agbaja iron ore were fired in the muffle furnace to $600^{\circ} \mathrm{C}$. After which they were subjected to load test by using the Testometric testing machine with M500-25CT the readings of the scattered load were observed as the samples were placed under the testing machine until fracture were observed and recorded. The results of the best six pellets samples were taken and recorded. The average values of the compressed sample reading gave the actual dry compressive strength test of the pellets. Same procedures were applied to the rest of the pellets. 


\subsection{Indurating Compressive Strength Test}

The indurating compressive strength test experiments were performed and observed where eight (8) samples of pellets were randomly selected and subjected to heating processes. The experiments were carried out using the muffle furnace at the Foundry Section in the Department of the Metallurgical and Materials Engineering, University of Nigeria, Nsukka. The only difference was that pellets tested in this group were fired in a heating furnace to a temperature of $1200^{\circ} \mathrm{C}$ for one hour, before the samples were subjected to load using the Testometric testing machine with M500-25CT .The readings of the scattered load were observed as the samples were placed under the testing machine until fracture were observed and the obtained values were recorded and the average of the readings of the best six samples results were taken as the actual indurating compressive strength test of the pellets. The same experimental procedures were repeated to the rest of the blends

\section{3...6 Moisture Content of Pellet in Each Blend}

Eight (8) pellet samples were randomly selected from a set of group of blended pellets produced. The sample were weighed using a digital weighing balance of model Electronic Scale $-\mathrm{C} \& \mathrm{G} \mathrm{GMbH}$ Gielensto 65-69 41460 Neuss, Germany, at the Nigerian Liquefied Natural Gas (NLNG), at the Faculty of Engineering, University of Nigeria, and Nsukka.

The moisture content of the samples were performed as they serves as a representative of the pellets of a blend that were taken and placed into a crucible which was thereafter weighed with the same weighing scale and the readings were carefully recorded, the crucible and pellets were then transferred into a heating oven with model DHG-9101 Laboratory Dry Oven also at the Nigerian Liquefied Natural Gas (NLNG), at the Faculty of Engineering, |University of Nigeria , Nsukka at a heating temperature at $105^{\circ} \mathrm{C}$ this process was allowed for two (2) hours after which they were brought out and weighed then were allow to cool down. The samples were then returned into the heating oven and then reheated for another one (1) hour, thereafter the samples were allowed to cool down and they were re- weighed; this process was done severally until other results were obtained for the required readings.

Weight of initial crucible + the sample $=\mathrm{W}_{1}$

Weight of final crucible + the sample $=\mathrm{W}_{2}$

Volume of $\mathrm{H}_{2} \mathrm{O}$ expelled from sample $=\mathrm{W}_{1^{-}} \mathrm{W}_{2}$

\subsection{Micro-Porosity of Pellet in Each Blend}

The micro-porosity of the pellets were performed, the weighted pellets were heated to $900^{\circ} \mathrm{C}$ using the muffle furnace, with model number LABE 1210, Divine International, Delhi. Thereafter, the samples were taken out of the furnace and were dropped into a beaker containing benzene; Immediately this was done, there were release of bubbles from the pellets which indicate that empty spaces in the pellets were filled with benzene displacing the blow of air which was filled with benzene and also displacing the blow of air within the pellets, which was caused by the firing of the pellets. The sample were allowed to remain in benzene solution until the bubbles stopped. The pellets were then brought out of benzene and quickly weighed. This was then repeated for all other samples from other blends.

$\%$ Porosity $=\frac{W t \text { of Pellets in Benzene }(D)-W t \text { of Pellets before immersion in Benzene }(d)}{W t \text { of Pellets in Benzene }(D)}$

$=\frac{\mathrm{D}-\mathrm{d}}{\mathrm{D}} \times 100 \%$

\subsection{Tumbler Resistance Test}

The tumbler resistance test were performed where 60 Pellets of 95\% Itakpe Iron ore and 5\% Agbaja iron ore blend were taken and weighed at $600 \mathrm{gms}$. The samples were thereafter fired and dried at $150^{\circ} \mathrm{c}$ slowly in a heating furnace for two (2) hours. Thereafter the pellets were introduced into a drum with diameter $0.25 \mathrm{~m}$, length $0.1 \mathrm{~m}$, with two (2) lifters each of height $0.25 \mathrm{~m}$ located inside the drum which was allowed to rotate for six (6) minutes at a speed of $24 \mathrm{rpm}$, after which the shattered pellets were screened and the fraction of $+0.63 \mathrm{~mm}$. The percentage of separated fractions in proportion to the feed weight was the value of tumbler index (i.e. +0.63$)$

Tumbler index value $=\frac{\text { Wt of Chattered Pellets at }-6.3 \mathrm{~mm}}{\text { Total wt of Pellets charged }}$ 


\subsection{Abrasion Index value}

The abrasion tests were carried out using 60 pellets samples of 95\% Itakpe Iron ore and 5\% Agbaja iron ore blend weighing $600 \mathrm{gms}$. The sample of the pellets were fired and dried at $150^{\circ} \mathrm{c}$ slowly in a heating furnace for two (2) hours. The samples were then removed from the furnace and placed into a drum with diameter $0.25 \mathrm{~m}$, length $0.1 \mathrm{~m}$, with two (2) lifters each of height $0.25 \mathrm{~m}$ located inside the drum which was allowed to rotate for six (6) minutes at a speed of $24 \mathrm{rpm}$, after which the shattered pellets were screened and the fraction $-0.5 \mathrm{~mm}$. The percentage of separated fractions in proportion to the feed weight was the value abrasion index (i.e. $-0.5 \mathrm{~mm}$ ).

Abrasion index value $=\frac{W \text { t of Chattered Pellets at }-0.5 \mathrm{~mm}}{\text { Total wt of Pellets charged }}$

The values obtained from the mechanical properties were calculated .The means, average, range and standard deviation (Sigma) of these six various properties were each calculated.

\section{Control Charts}

Quality control chart was constructed for means and standard deviation (Sigma) value. A control chart has three horizontal lines drawn across the sample value. The central line represents the mean value. The upper Control Limit (UCL) represents the chemical compositions and hardness values of means + $3 x$ Sigma. The Lower Control Limit (LCL) represents the mechanical properties and average and range values of means $-3 x$ Sigma [5]. The mean values obtained from various samples were plotted in diagrams.

The aim of using these processes is to determine whether the point or points fall within the band of UCL and LCL, the process is said to be under control on a statistical sense, when the points show trend of moving toward UCL or LCL, thereby indicating that the process may get out of control limits when the points fell outside the limits indicating out of control. [6]

\subsection{The statistical basis for control charts is as follows}

It is assumed that the mechanical properties value of measurements should follow normal (Gaussian) distribution: Then if only $2 \%$ of the measured values fell outside the 3sigma limit, the process is still believed to be outside the control limits in the control chart. This is considered as acceptable condition for quality; if the mean value fell outside the limits, it indicates that the process is out of control. [7]

\subsection{Range}

(R-Chart) is defined as maximum value - minimum value. Range is related to sigma and therefore control chart can be drawn using range chart as was constructed with UCL and LCL [8]

\section{RESEARCH METHODS}

The research was performed by determining the mechanical properties of the samples the produced pellets. The samples were tested using various equipment since they have unique tests that was performed.

\subsection{Mechanical Properties of Blend Itakpe and Agbaja Iron Ore Lumps for the Production of Pellets}

The mechanical properties of the blended iron ore pellets produced were investigated to evaluate the possibility of using the blend mixture to produce liquid pig iron in the blast furnace and also in the Direct Reduced Iron (DRI) process. The mechanical properties investigated are : Drop Number(DN),Drop Resistance(DR),Green Compression Strength Test(GCST),Dry Compression Strength Test(DCST), Indurating Compressive Strength Values( ICSV), Moisture Content (MC), Tumbler Index Value (TIV), Abrasion Index value(AIV) and Micro Porosity(MP) which constituents the major criteria or parameters used in selecting acceptable samples blend for the production of pellets as bases for performing this research work. The details of the results could be found on table 5.1 - 5.9. These table contains the results obtained when the experiments were performed. The table also consist of the six test results, averages, the standard deviation and ranges which are calculated and put in various tables for further statistical analyses.

\subsection{Statistical Quality Control}

\subsubsection{Control Charts}

Two control charts were used where values from the samples were directly plotted. Various values were determined, where, the average and the range value of the samples were determined. The charts 
contained control limits (previously calculated using statistical principles) and the samples values checked against the control limits. There are normally two levels of control limit a Warning limit and an Action Limit [9]. Action can only be taken if any plotted value was outside the control limits, action could then be taken to trace the specific cause of the variation and necessary corrections made, which assisted in reducing production errors of pellet produced and limit the numbers of pellets that could be rejected from the production process and the pellets produced that were not of the acceptable specifications values were not accepted. This is because the production of pellets for steel productions have general international standards that must be met before they could be accepted for meeting the requirements of good and quality pellets produced.

The charts were further used to provide a visual means of distinguishing between the variability due to inherent causes (process in control) and the variability due to special causes (process out of control). The results obtained were used and can be understood by people with little or no statistical background.

Two types of control charts were used in this research work the $\bar{X}$ - Chart and $\overline{\mathrm{R}}$ - Chart

The calculations for the $\overline{\bar{X}}$ control chart use $\mathrm{X}=\frac{\sum_{j}^{n}=1 X_{i}}{n}----1$

Which define the sample average $\bar{x}$, that is, the average of the samples units (for some variable measurement); the average $\bar{x}$ of the sample averages, the standard deviation $\left(s_{x}^{-}\right)$of the distribution of the sample averages and Upper Control Limit and Lower Control Limit

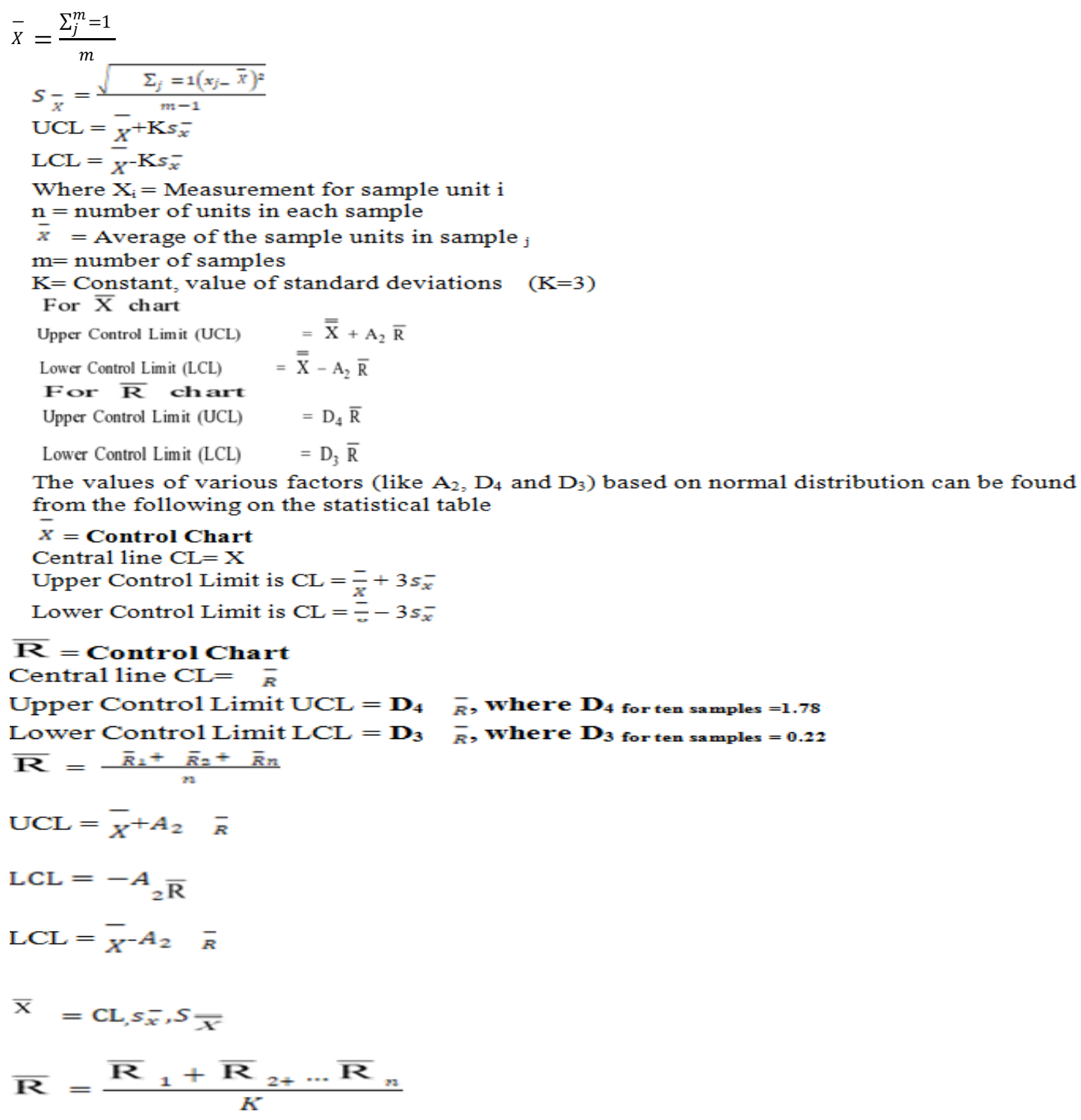


Statistical Quality Control on the Mechanical Properties on Resultant Pellets of Itakpe And Agbaja Iron Ore Blends

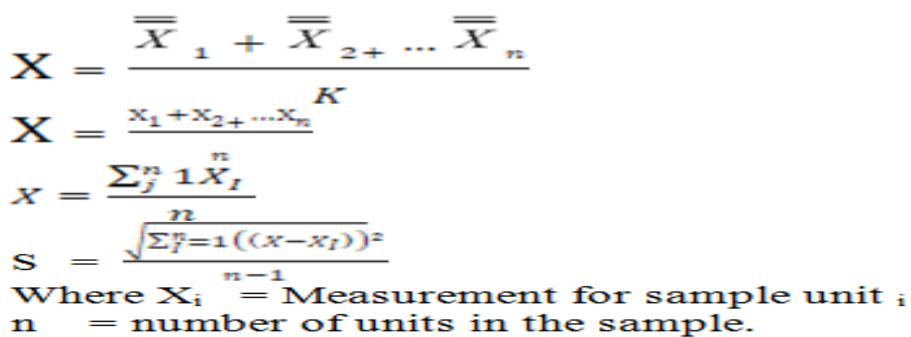

Table5.1. Drop Number Test @ $60 \mathrm{~cm}$

\begin{tabular}{|c|c|c|c|c|c|c|c|c|c|c|}
\hline S/NO & 1 & 2 & 3 & 4 & 5 & 6 & Average & $\begin{array}{l}\text { Standrad } \\
\text { Deviation }\end{array}$ & & Range \\
\hline $100 / 0.00$ & 3.20 & 3.25 & 3.24 & 3.25 & 3.24 & 3.20 & 3.23 & 0.00 & & 0.05 \\
\hline $95 / 5.00$ & 3.23 & 3.26 & 3.27 & 3.24 & 3.25 & 3.23 & 3.25 & 0.00 & & 0.04 \\
\hline $90 / 10.00$ & 3.35 & 3.36 & 3.35 & 3.34 & 3.35 & 3.35 & 3.35 & 0.01 & & 0.02 \\
\hline $85 / 15.00$ & 3.41 & 3.40 & 3.42 & 3.43 & 3.42 & 3.41 & 3.42 & 0.02 & & 0.03 \\
\hline $80 / 20.00$ & 3.45 & 3.43 & 3.44 & 3.46 & 3.45 & 3.45 & 3.45 & 0.04 & & 0.03 \\
\hline $75 / 25.00$ & 3.55 & 3.54 & 3.54 & 3.55 & 3.55 & 3.55 & 3.55 & 0.08 & & 0.01 \\
\hline $70 / 30.00$ & 3.88 & 3.89 & 3.89 & 3.89 & 3.89 & 3.88 & 3.89 & 0.40 & & 0.01 \\
\hline $65 / 35.00$ & 3.68 & 3.66 & 3.65 & 3.67 & 3.67 & 3.68 & 3.67 & 0.17 & & 0.03 \\
\hline $60 / 40.00$ & 3.65 & 3.65 & 3.65 & 3.65 & 3.65 & 3.65 & 3.65 & 0.15 & & 0.00 \\
\hline $55 / 45.00$ & 3.57 & 3.57 & 3.58 & 3.57 & 3.58 & 3.57 & 3.57 & 0.10 & & 0.01 \\
\hline $50 / 50.00$ & 3.45 & 3.46 & 3.45 & 3.46 & 3.45 & 3.46 & 3.46 & 0.04 & & 0.01 \\
\hline $45 / 55.00$ & 3.42 & 3.40 & 3.42 & 3.44 & 3.42 & 3.42 & 3.42 & 0.03 & & 0.04 \\
\hline $40 / 60.00$ & 3.36 & 3.37 & 3.38 & 3.38 & 3.37 & 3.36 & 3.37 & 0.01 & & 0.02 \\
\hline $35 / 65.00$ & 3.24 & 3.26 & 3.28 & 3.25 & 3.26 & 3.24 & 3.26 & 0.00 & & 0.04 \\
\hline $30 / 70.00$ & 3.18 & 3.15 & 3.14 & 3.18 & 3.16 & 3.18 & 3.17 & 0.01 & & 0.03 \\
\hline $25 / 75.00$ & 3.09 & 3.07 & 3.05 & 3.06 & 3.07 & 3.09 & 3.07 & 0.03 & & 0.04 \\
\hline $20 / 80.00$ & 2.99 & 2.98 & 2.96 & 2.95 & 2.97 & 2.99 & 2.97 & 0.08 & & 0.03 \\
\hline $15 / 85.00$ & 2.89 & 2.88 & 2.87 & 2.89 & 2.88 & 2.89 & 2.88 & 0.14 & & 0.02 \\
\hline $10 / 90.00$ & 2.77 & 2.78 & 2.76 & 2.75 & 2.76 & 2.77 & 2.77 & 0.24 & & 0.03 \\
\hline $5 / 95.00$ & 2.56 & 2.57 & 2.55 & 2.59 & 2.57 & 2.56 & 2.57 & 0.48 & & 0.04 \\
\hline \multirow[t]{5}{*}{$0 / 100.00$} & 2.44 & 2.46 & 2.46 & 2.48 & 2.46 & 2.44 & 2.46 & 0.64 & & 0.04 \\
\hline & & & & & & & 68.40 & 2.68 & & 0.57 \\
\hline & & & & & & CL & 3.26 & 0.37 & CL & 0.03 \\
\hline & & & & & & UCL & 4.36 & & UCL & 0.05 \\
\hline & & & & & & LCL & 2.16 & & LCL & 0.01 \\
\hline
\end{tabular}

Table 5.2. Drop Resistance Test @ $48 \mathrm{~cm}, 60 \mathrm{~cm} \& 72 \mathrm{~cm}$

\begin{tabular}{|l|l|l|l|l|l|l|l|l|l|l|}
\hline S/NO & 1 & 2 & 3 & 4 & 5 & 6 & Average & $\begin{array}{l}\text { Standrad } \\
\text { Deviation }\end{array}$ & Range \\
\hline $100 / 0.00$ & 3.80 & 3.82 & 3.81 & 3.83 & 3.82 & 3.80 & 3.81 & 0.05 & 0.03 \\
\hline $95 / 5.00$ & 3.88 & 3.89 & 3.88 & 3.87 & 3.88 & 3.88 & 3.88 & 0.03 & & 0.02 \\
\hline $90 / 10.00$ & 4.06 & 4.08 & 4.09 & 4.07 & 4.08 & 4.06 & 4.07 & 0.00 & 0.03 \\
\hline $85 / 15.00$ & 4.13 & 4.12 & 4.13 & 4.14 & 4.15 & 4.13 & 4.13 & 0.01 & & 0.01 \\
\hline $80 / 20.00$ & 4.25 & 4.27 & 4.29 & 4.28 & 4.27 & 4.25 & 4.27 & 0.05 & 0.08 & 0.03 \\
\hline $75 / 25.00$ & 4.31 & 4.33 & 4.34 & 4.35 & 4.33 & 4.31 & 4.33 & 0.08 & 0.04 \\
\hline $70 / 30.00$ & 4.45 & 4.47 & 4.48 & 4.48 & 4.47 & 4.45 & 4.47 & 0.18 & 0.03 \\
\hline $65 / 35.00$ & 4.56 & 4.58 & 4.57 & 4.59 & 4.58 & 4.56 & 4.57 & 0.28 & 0.03 \\
\hline $60 / 40.00$ & 4.66 & 4.68 & 4.66 & 4.69 & 4.67 & 4.69 & 4.68 & 0.40 & & 0.03 \\
\hline $55 / 45.00$ & 4.69 & 4.66 & 4.67 & 4.65 & 4.67 & 4.69 & 4.67 & 0.39 & & 0.04 \\
\hline $50 / 50.00$ & 4.79 & 4.77 & 4.76 & 4.79 & 4.78 & 4.79 & 4.78 & 0.54 & & 0.03 \\
\hline $45 / 55.00$ & 4.56 & 4.53 & 4.53 & 4.46 & 4.44 & 4.43 & 4.49 & 0.20 & & 0.13 \\
\hline $40 / 60.00$ & 4.35 & 4.39 & 4.37 & 4.35 & 4.37 & 4.35 & 4.36 & 0.10 & & 0.04 \\
\hline $35 / 65.00$ & 4.23 & 4.26 & 4.21 & 4.22 & 4.23 & 4.23 & 4.23 & 0.03 & & 0.03 \\
\hline $30 / 70.00$ & 4.15 & 4.17 & 4.19 & 4.19 & 4.18 & 4.15 & 4.17 & 0.02 & & 0.04 \\
\hline $25 / 75.00$ & 4.01 & 4.02 & 4.05 & 4.02 & 4.03 & 4.01 & 4.02 & 0.00 & & 0.04 \\
\hline $20 / 80.00$ & 3.48 & 3.49 & 3.46 & 3.45 & 3.47 & 3.48 & 3.47 & 0.33 & & 0.04 \\
\hline $15 / 85.00$ & 3.32 & 3.31 & 3.33 & 3.34 & 3.33 & 3.32 & 3.33 & 0.52 & & 0.03 \\
\hline
\end{tabular}


Statistical Quality Control on the Mechanical Properties on Resultant Pellets of Itakpe And Agbaja Iron Ore Blends

\begin{tabular}{|l|l|l|l|l|l|l|l|l|l|l|}
\hline $10 / 90.00$ & 3.11 & 3.12 & 3.13 & 3.13 & 3.12 & 3.11 & 3.12 & 0.86 & & 0.02 \\
\hline $5 / 95.00$ & 3.08 & 3.07 & 3.09 & 3.08 & 3.08 & 3.08 & 3.08 & 0.93 & & 0.02 \\
\hline $0 / 100.00$ & 3.02 & 3.01 & 3.00 & 3.02 & 3.01 & 3.02 & 3.01 & 1.07 & & 0.01 \\
\hline & & & & & & & $\mathbf{8 4 . 9 5}$ & $\mathbf{6 . 0 6}$ & & $\mathbf{0 . 7 2}$ \\
\hline & & & & & & CL & $\mathbf{4 . 0 5}$ & $\mathbf{0 . 5 5}$ & CL & $\mathbf{0 . 0 3}$ \\
\hline & & & & & & UCL & $\mathbf{5 . 7 0}$ & & UCL & $\mathbf{0 . 0 6}$ \\
\hline & & & & & & LCL & $\mathbf{2 . 3 9}$ & & LCL & $\mathbf{0 . 0 1}$ \\
\hline
\end{tabular}

Table5.3. Green Compressive Strength Test

\begin{tabular}{|l|l|l|l|l|l|l|l|l|l|l|}
\hline S/NO & 1 & 2 & 3 & 4 & 5 & 6 & Average & $\begin{array}{l}\text { Standrad } \\
\text { Deviation }\end{array}$ & & Range \\
\hline $100 / 0.00$ & 36.5 & 36.5 & 36.4 & 36.4 & 36.5 & 36.4 & 36.44 & 154.78 & 0.02 \\
\hline $95 / 5.00$ & 36.4 & 36.4 & 36.3 & 36.3 & 36.4 & 36.3 & 36.35 & 152.39 & & 0.01 \\
\hline $90 / 10.00$ & 33.1 & 33.1 & 33.1 & 33.1 & 33.1 & 33.1 & 33.12 & 83.07 & & 0.01 \\
\hline $85 / 15.00$ & 33.3 & 33.3 & 33.3 & 33.3 & 33.3 & 33.3 & 33.33 & 86.95 & & 0.02 \\
\hline $80 / 20.00$ & 33.5 & 33.5 & 33.5 & 33.5 & 33.5 & 33.5 & 33.47 & 89.64 & & 0.03 \\
\hline $75 / 25.00$ & 33.9 & 33.9 & 33.9 & 33.9 & 33.9 & 33.9 & 33.86 & 97.27 & & 0.02 \\
\hline $70 / 30.00$ & 34.7 & 34.7 & 34.7 & 34.7 & 34.7 & 34.7 & 34.70 & 114.37 & & 0.02 \\
\hline $65 / 35.00$ & 35.1 & 35.1 & 35.1 & 35.1 & 35.1 & 35.1 & 35.08 & 122.79 & & 0.02 \\
\hline $60 / 40.00$ & 31.5 & 31.5 & 31.5 & 31.5 & 31.5 & 31.5 & 31.48 & 55.87 & & 0.03 \\
\hline $55 / 45.00$ & 25.4 & 25.4 & 25.4 & 25.5 & 25.4 & 25.4 & 25.44 & 2.08 & & 0.01 \\
\hline $50 / 50.00$ & 17 & 17 & 17 & 17 & 17 & 17 & 16.96 & 49.57 & & 0.04 \\
\hline $45 / 55.00$ & 17 & 16.9 & 17 & 16.9 & 16.9 & 17 & 16.95 & 49.73 & & 0.02 \\
\hline $40 / 60.00$ & 18.3 & 18.3 & 18.3 & 18.3 & 18.3 & 18.3 & 18.30 & 32.50 & & 0.04 \\
\hline $35 / 65.00$ & 18 & 18 & 18 & 18 & 18 & 18 & 17.96 & 36.47 & & 0.03 \\
\hline $30 / 70.00$ & 16 & 16 & 16 & 16 & 16 & 15.9 & 15.96 & 64.73 & & 0.03 \\
\hline $25 / 75.00$ & 15.8 & 15.8 & 15.7 & 15.7 & 15.7 & 15.7 & 15.74 & 68.21 & & 0.03 \\
\hline $20 / 80.00$ & 15.7 & 15.7 & 15.7 & 15.7 & 15.7 & 15.7 & 15.67 & 69.37 & & 0.04 \\
\hline $15 / 85.00$ & 15 & 15 & 15 & 14.9 & 15 & 14.9 & 14.96 & 81.70 & & 0.05 \\
\hline $10 / 90.00$ & 13.9 & 13.9 & 13.9 & 13.9 & 13.9 & 13.9 & 13.91 & 101.85 & & 0.04 \\
\hline $5 / 95.00$ & 12.5 & 12.4 & 12.4 & 12.4 & 12.4 & 12.4 & 12.42 & 134.19 & & 0.06 \\
\hline $0 / 100.00$ & 12 & 11.9 & 11.9 & 11.9 & 11.9 & 11.9 & 11.94 & 145.58 & & 0.05 \\
\hline & & & & & & & 504.01 & 1793.10 & & 0.62 \\
\hline & & & & & & CL & 24.00 & 0.37 & CL & 0.03 \\
\hline & & & & & & UCL & 25.10 & & UCL & 0.05 \\
\hline & & & & & & LCL & 22.90 & & LCL & 0.01 \\
\hline
\end{tabular}

Table5.4. Dry Compressive Strength Test @ 6000C. (N/P)

\begin{tabular}{|l|l|l|l|l|l|l|l|l|l|l|}
\hline S/NO & 1 & 2 & 3 & 4 & 5 & 6 & Average & $\begin{array}{l}\text { Standrad } \\
\text { Deviation }\end{array}$ & & Range \\
\hline $100 / 0.00$ & 36.45 & 36.45 & 36.43 & 36.44 & 36.45 & 36.43 & 36.44 & 0.01 & 0.02 \\
\hline $95 / 5.00$ & 36.35 & 36.35 & 36.34 & 36.34 & 36.35 & 36.34 & 36.35 & 0.00 & 0.01 \\
\hline $90 / 10.00$ & 36.35 & 36.35 & 36.34 & 36.34 & 36.35 & 36.34 & 36.35 & 0.56 & 0.01 \\
\hline $85 / 15.00$ & 36.35 & 36.35 & 36.34 & 36.34 & 36.35 & 36.34 & 36.35 & 0.54 & & 0.01 \\
\hline $80 / 20.00$ & 36.36 & 36.35 & 36.34 & 36.34 & 36.35 & 36.34 & 36.35 & 1321.08 & 0.02 \\
\hline $75 / 25.00$ & 36.35 & 36.35 & 36.34 & 36.34 & 36.35 & 36.34 & 36.35 & 1320.96 & 0.01 \\
\hline $70 / 30.00$ & 36.35 & 36.35 & 36.34 & 36.36 & 36.35 & 36.34 & 36.35 & 1321.20 & 0.02 \\
\hline $65 / 35.00$ & 36.35 & 36.35 & 36.34 & 36.34 & 36.35 & 36.34 & 36.35 & 1320.96 & 0.01 \\
\hline $60 / 40.00$ & 36.35 & 36.35 & 36.34 & 36.34 & 36.35 & 36.34 & 36.35 & 1320.96 & 0.01 \\
\hline $55 / 45.00$ & 36.35 & 36.35 & 36.34 & 36.36 & 36.35 & 36.34 & 36.35 & 1321.20 & 0.02 \\
\hline $50 / 50.00$ & 36.35 & 36.35 & 36.34 & 36.34 & 36.35 & 36.34 & 36.35 & 1320.96 & 0.01 \\
\hline $45 / 55.00$ & 36.37 & 36.35 & 36.34 & 36.34 & 36.35 & 36.34 & 36.35 & 1321.20 & 0.02 \\
\hline $40 / 60.00$ & 36.35 & 36.35 & 36.34 & 36.34 & 36.35 & 36.34 & 36.35 & 1320.96 & 0.01 \\
\hline $35 / 65.00$ & 36.35 & 36.35 & 36.34 & 36.34 & 36.35 & 36.34 & 36.35 & 1320.96 & 0.01 \\
\hline $30 / 70.00$ & 36.35 & 36.35 & 36.34 & 36.34 & 36.35 & 36.34 & 36.35 & 1320.96 & & 0.01 \\
\hline $25 / 75.00$ & 36.35 & 36.35 & 36.34 & 36.34 & 36.35 & 36.34 & 36.35 & 1320.96 & 0.01 \\
\hline $20 / 80.00$ & 36.35 & 36.35 & 36.34 & 36.34 & 36.35 & 36.34 & 36.35 & 1320.96 & 0.01 \\
\hline $15 / 85.00$ & 36.35 & 36.35 & 36.34 & 36.34 & 36.35 & 36.34 & 36.35 & 1320.96 & 0.01 \\
\hline $10 / 90.00$ & 36.35 & 36.35 & 36.34 & 36.34 & 36.35 & 36.36 & 36.35 & 1321.20 & & 0.02 \\
\hline
\end{tabular}


Statistical Quality Control on the Mechanical Properties on Resultant Pellets of Itakpe And Agbaja Iron Ore Blends

\begin{tabular}{|l|l|l|l|l|l|l|l|l|l|l|l|}
\hline $5 / 95.00$ & 36.35 & 36.35 & 36.34 & 36.34 & 36.35 & 36.34 & 36.35 & 1320.96 & & 0.01 \\
\hline $0 / 100.00$ & 36.35 & 36.35 & 36.34 & 36.34 & 36.35 & 36.34 & 36.35 & 1320.96 & & 0.01 \\
\hline & & & & & & & 763.36 & 582713.40 & & 0.27 \\
\hline & & & & & & CL & 36.35 & 0.25 & CL & 0.01 \\
\hline & & & & & & UCL & 37.09 & & UCL & 0.02 \\
\hline & & & & & & LCL & 35.61 & & LCL & 0.00 \\
\hline
\end{tabular}

Table5.5. Indurating Compressive Strength Test@ $12000 C(N / P)$

\begin{tabular}{|c|c|c|c|c|c|c|c|c|c|c|}
\hline S/NO & 1 & 2 & 3 & 4 & 5 & 6 & Average & $\begin{array}{l}\text { Standrad } \\
\text { Deviation }\end{array}$ & & Range \\
\hline $100 / 0.00$ & 2212.46 & 2212.41 & 2212.44 & 2212.44 & 2212.46 & 2212.45 & 2212.44 & 2079.67 & & 0.05 \\
\hline $95 / 5.00$ & 2323.67 & 2323.61 & 2323.64 & 2323.62 & 2323.67 & 2323.61 & 2323.64 & 4302.04 & & 0.06 \\
\hline $90 / 10.00$ & 2436.39 & 2436.32 & 2436.35 & 2436.34 & 2436.39 & 2436.32 & 2436.35 & 31792.64 & & 0.07 \\
\hline $85 / 15.00$ & 2439.55 & 2439.47 & 2439.53 & 2439.49 & 2439.55 & 2439.47 & 2439.51 & 32928.91 & & 0.08 \\
\hline $80 / 20.00$ & 2456.72 & 2456.67 & 2456.69 & 2456.71 & 2456.72 & 2456.68 & 2456.70 & 39462.45 & & 0.05 \\
\hline $75 / 25.00$ & 2461.56 & 2461.51 & 2461.52 & 2461.51 & 2461.56 & 2461.51 & 2461.53 & 41404.76 & & 0.05 \\
\hline $70 / 30.00$ & 2592.45 & 2592.38 & 2592.40 & 2592.38 & 2592.45 & 2592.35 & 2592.40 & 111793.21 & & 0.07 \\
\hline $65 / 35.00$ & 2596.33 & 2596.28 & 2596.30 & 2596.29 & 2596.33 & 2596.28 & 2596.30 & 114416.39 & & 0.05 \\
\hline $60 / 40.00$ & 2547.73 & 2547.69 & 2547.69 & 2547.71 & 2547.73 & 2547.71 & 2547.71 & 83904.80 & & 0.04 \\
\hline $55 / 45.00$ & 2455.29 & 2455.24 & 2455.26 & 2455.25 & 2455.29 & 2455.28 & 2455.27 & 38896.35 & & 0.05 \\
\hline $50 / 50.00$ & 2387.09 & 2387.08 & 2387.09 & 2387.09 & 2387.06 & 2387.08 & 2387.08 & 16650.01 & & 0.03 \\
\hline $45 / 55.00$ & 2186.20 & 2186.18 & 2186.18 & 2186.16 & 2186.20 & 2186.18 & 2186.18 & 5164.35 & & 0.04 \\
\hline $40 / 60.00$ & 2138.11 & 2138.07 & 2138.10 & 2138.09 & 2138.11 & 2138.09 & 2138.10 & 14388.42 & & 0.04 \\
\hline $35 / 65.00$ & 2097.09 & 2097.05 & 2096.08 & 2097.09 & 2097.09 & 2096.08 & 2096.75 & 26017.72 & & 0.04 \\
\hline $30 / 70.00$ & 2097.55 & 2097.49 & 2097.49 & 2097.48 & 2097.55 & 2097.46 & 2097.50 & 25774.19 & & 0.07 \\
\hline $25 / 75.00$ & 2085.91 & 2085.89 & 2085.89 & 2085.86 & 2085.91 & 2085.89 & 2085.89 & 29637.37 & & 0.05 \\
\hline $20 / 80.00$ & 2035.78 & 2035.74 & 2035.79 & 2035.79 & 2035.78 & 2035.78 & 2035.78 & 49403.99 & & 0.05 \\
\hline $15 / 85.00$ & 1992.66 & 1992.68 & 1992.64 & 1992.66 & 1992.66 & 1992.68 & 1992.66 & 70428.36 & & 0.04 \\
\hline $10 / 90.00$ & 1992.39 & 1992.33 & 1992.39 & 1992.39 & 1992.39 & 1992.34 & 1992.37 & 70583.25 & & 0.06 \\
\hline $5 / 95.00$ & 1992.11 & 1992.06 & 1992.10 & 1992.08 & 1992.07 & 1992.06 & 1992.08 & 70738.31 & & 0.05 \\
\hline \multirow[t]{5}{*}{$0 / 100.00$} & 1892.78 & 1892.75 & 1892.61 & 1892.76 & 1892.78 & 1892.75 & 1892.74 & 133450.24 & & 0.03 \\
\hline & & & & & & & 47418.98 & 1013217.43 & & 1.07 \\
\hline & & & & & & $\mathrm{CL}$ & 2258.05 & 225.08 & $\mathrm{CL}$ & 0.05 \\
\hline & & & & & & UCL & 2933.29 & & UCL & 0.09 \\
\hline & & & & & & LCL & 1582.81 & & LCL & 0.01 \\
\hline
\end{tabular}

Table5.6. Moisture Content per Pellet $(\mathrm{ml})$

\begin{tabular}{|c|c|c|c|c|c|c|c|c|c|c|}
\hline S/NO & 1 & 2 & 3 & 4 & 5 & 6 & Average & $\begin{array}{l}\text { Standrad } \\
\text { Deviation }\end{array}$ & & Range \\
\hline $100 / 0.00$ & 3.93 & 3.94 & 3.92 & 3.92 & 3.93 & 3.94 & 3.93 & 1.84 & & 0.02 \\
\hline $95 / 5.00$ & 4.86 & 4.84 & 4.89 & 4.85 & 4.87 & 4.84 & 4.86 & 0.18 & & 0.05 \\
\hline $90 / 10.00$ & 4.72 & 4.75 & 4.74 & 4.73 & 4.72 & 4.75 & 4.74 & 0.31 & & 0.03 \\
\hline $85 / 15.00$ & 4.88 & 4.87 & 4.85 & 4.84 & 4.85 & 4.84 & 4.86 & 0.19 & & 0.04 \\
\hline $80 / 20.00$ & 4.98 & 4.95 & 4.95 & 4.96 & 4.99 & 4.98 & 4.97 & 0.10 & & 0.04 \\
\hline $75 / 25.00$ & 5.14 & 5.16 & 5.14 & 5.14 & 5.14 & 5.19 & 5.15 & 0.02 & & 0.03 \\
\hline $70 / 30.00$ & 5.22 & 5.22 & 5.23 & 5.24 & 5.25 & 5.26 & 5.24 & 0.00 & & 0.04 \\
\hline $65 / 35.00$ & 5.57 & 5.58 & 5.59 & 5.61 & 5.57 & 5.58 & 5.58 & 0.09 & & 0.04 \\
\hline $60 / 40.00$ & 5.83 & 5.84 & 5.85 & 5.85 & 5.83 & 5.84 & 5.84 & 0.30 & & 0.02 \\
\hline $55 / 45.00$ & 6.12 & 6.12 & 6.14 & 6.14 & 6.13 & 6.14 & 6.13 & 0.71 & & 0.02 \\
\hline $50 / 50.00$ & 6.76 & 6.78 & 6.76 & 6.79 & 6.75 & 6.80 & 6.77 & 2.21 & & 0.04 \\
\hline $45 / 55.00$ & 6.50 & 6.51 & 6.52 & 6.51 & 6.52 & 6.45 & 6.50 & 1.47 & & 0.02 \\
\hline $40 / 60.00$ & 6.35 & 6.30 & 6.31 & 6.35 & 6.32 & 6.30 & 6.32 & 1.07 & & 0.05 \\
\hline $35 / 65.00$ & 5.79 & 5.73 & 5.74 & 5.74 & 5.73 & 5.73 & 5.74 & 0.21 & & 0.05 \\
\hline $30 / 70.00$ & 5.73 & 5.73 & 5.72 & 5.70 & 5.73 & 5.73 & 5.72 & 0.19 & & 0.03 \\
\hline $25 / 75.00$ & 4.85 & 4.82 & 4.82 & 4.84 & 4.85 & 4.82 & 4.83 & 0.21 & & 0.03 \\
\hline $20 / 80.00$ & 4.96 & 4.94 & 4.92 & 4.95 & 4.96 & 4.94 & 4.95 & 0.12 & & 0.04 \\
\hline $15 / 85.00$ & 4.82 & 4.79 & 4.80 & 4.81 & 4.82 & 4.79 & 4.81 & 0.23 & & 0.03 \\
\hline $10 / 90.00$ & 4.76 & 4.75 & 4.73 & 4.72 & 4.76 & 4.75 & 4.75 & 0.29 & & 0.03 \\
\hline $5 / 95.00$ & 4.71 & 4.73 & 4.73 & 4.72 & 4.71 & 4.73 & 4.72 & 0.32 & & 0.02 \\
\hline \multirow[t]{5}{*}{$0 / 100.00$} & 4.66 & 4.65 & 4.64 & 4.62 & 4.66 & 4.65 & 4.65 & 0.41 & & 0.04 \\
\hline & & & & & & & 111.05 & 10.48 & & 0.71 \\
\hline & & & & & & $\mathrm{CL}$ & 5.29 & 0.72 & $\mathrm{CL}$ & 0.03 \\
\hline & & & & & & UCL & 7.46 & & UCL & 0.06 \\
\hline & & & & & & LCL & 3.12 & & LCL & 0.01 \\
\hline
\end{tabular}


Statistical Quality Control on the Mechanical Properties on Resultant Pellets of Itakpe And Agbaja Iron Ore Blends

Table5.7. Timber Index Test (\%)

\begin{tabular}{|c|c|c|c|c|c|c|c|c|c|c|}
\hline S/NO & 1 & 2 & 3 & 4 & 5 & 6 & Average & $\begin{array}{l}\text { Standrad } \\
\text { Deviation }\end{array}$ & & Range \\
\hline $100 / 0.00$ & 93.15 & 93.12 & 93.12 & 93.12 & 93.12 & 93.12 & 93.13 & 0.19 & & 0.03 \\
\hline $95 / 5.00$ & 93.28 & 93.26 & 93.26 & 93.26 & 93.26 & 93.26 & 93.26 & 0.09 & & 0.02 \\
\hline $90 / 10.00$ & 93.33 & 93.33 & 93.33 & 93.35 & 93.37 & 93.37 & 93.35 & 0.05 & & 0.04 \\
\hline $85 / 15.00$ & 93.37 & 93.37 & 93.35 & 93.37 & 93.37 & 93.33 & 93.36 & 0.04 & & 0.04 \\
\hline $80 / 20.00$ & 93.42 & 93.41 & 93.41 & 93.43 & 93.45 & 93.45 & 93.43 & 0.02 & & 0.04 \\
\hline $75 / 25.00$ & 93.45 & 93.47 & 93.47 & 93.48 & 93.49 & 93.49 & 93.48 & 0.01 & & 0.04 \\
\hline $70 / 30.00$ & 93.66 & 93.63 & 93.63 & 93.62 & 93.63 & 93.63 & 93.63 & 0.01 & & 0.04 \\
\hline $65 / 35.00$ & 93.67 & 93.69 & 93.69 & 93.72 & 93.7 & 93.7 & 93.70 & 0.02 & & 0.05 \\
\hline $60 / 40.00$ & 93.84 & 93.84 & 93.84 & 93.88 & 93.83 & 93.83 & 93.84 & 0.08 & & 0.04 \\
\hline $55 / 45.00$ & 93.79 & 93.78 & 93.77 & 93.76 & 93.77 & 93.76 & 93.77 & 0.04 & & 0.03 \\
\hline $50 / 50.00$ & 93.75 & 93.76 & 93.74 & 93.74 & 93.76 & 93.77 & 93.75 & 0.04 & & 0.03 \\
\hline $45 / 55.00$ & 93.72 & 93.75 & 93.73 & 93.74 & 93.75 & 93.73 & 93.74 & 0.03 & & 0.03 \\
\hline $40 / 60.00$ & 93.7 & 93.7 & 93.71 & 93.7 & 93.71 & 93.7 & 93.70 & 0.02 & & 0.01 \\
\hline $35 / 65.00$ & 93.69 & 93.67 & 93.68 & 93.67 & 93.66 & 93.67 & 93.67 & 0.01 & & 0.02 \\
\hline $30 / 70.00$ & 93.67 & 93.66 & 93.65 & 93.64 & 93.63 & 93.64 & 93.65 & 0.01 & & 0.03 \\
\hline $25 / 75.00$ & 93.65 & 93.64 & 93.63 & 93.62 & 93.63 & 93.66 & 93.64 & 0.01 & & 0.04 \\
\hline $20 / 80.00$ & 93.63 & 93.62 & 93.62 & 93.61 & 93.6 & 93.63 & 93.62 & 0.00 & & 0.03 \\
\hline $15 / 85.00$ & 93.6 & 93.59 & 93.6 & 93.61 & 93.6 & 93.59 & 93.60 & 0.00 & & 0.02 \\
\hline $10 / 90.00$ & 93.56 & 93.57 & 93.54 & 93.58 & 93.57 & 93.56 & 93.56 & 0.00 & & 0.04 \\
\hline $5 / 95.00$ & 93.48 & 93.49 & 93.49 & 93.49 & 93.48 & 93.48 & 93.49 & 0.01 & & 0.01 \\
\hline \multirow[t]{5}{*}{$0 / 100.00$} & 93.41 & 93.42 & 93.43 & 93.44 & 93.45 & 93.46 & 93.44 & 0.02 & & 0.05 \\
\hline & & & & & & & 1964.80 & 0.68 & & 0.68 \\
\hline & & & & & & $\mathrm{CL}$ & 93.56 & 0.18 & $\mathrm{CL}$ & 0.03 \\
\hline & & & & & & UCL & 94.11 & & UCL & 0.06 \\
\hline & & & & & & LCL & 93.01 & & LCL & 0.01 \\
\hline
\end{tabular}

Table5.8. Abrasion index value (\%)

\begin{tabular}{|c|c|c|c|c|c|c|c|c|c|c|}
\hline $\mathrm{S} / \mathrm{NO}$ & 1 & 2 & 3 & 4 & 5 & 6 & Average & $\begin{array}{l}\text { Standrad } \\
\text { Deviation }\end{array}$ & & Range \\
\hline $100 / 0.00$ & 4.41 & 4.36 & 4.39 & 4.39 & 4.38 & 4.36 & 4.38 & 0.00 & & 0.03 \\
\hline $95 / 5.00$ & 4.24 & 4.21 & 4.25 & 4.29 & 4.23 & 4.21 & 4.24 & 0.04 & & 0.03 \\
\hline $90 / 10.00$ & 4.05 & 4.05 & 4.03 & 4.05 & 4.04 & 4.05 & 4.05 & 0.15 & & 0.02 \\
\hline $85 / 15.00$ & 4.02 & 4.02 & 4.01 & 4.02 & 4.04 & 4.02 & 4.02 & 0.17 & & 0.02 \\
\hline $80 / 20.00$ & 4.01 & 4.02 & 4 & 4.01 & 4.01 & 4.02 & 4.01 & 0.18 & & 0.02 \\
\hline $75 / 25.00$ & 4.26 & 4.23 & 4.23 & 4.26 & 4.23 & 4.23 & 4.24 & 0.04 & & 0.03 \\
\hline $70 / 30.00$ & 4.34 & 4.34 & 4.32 & 4.34 & 4.33 & 4.34 & 4.34 & 0.01 & & 0.02 \\
\hline $65 / 35.00$ & 4.41 & 4.41 & 4.42 & 4.41 & 4.43 & 4.41 & 4.42 & 0.00 & & 0.02 \\
\hline $60 / 40.00$ & 4.6 & 4.59 & 4.59 & 4.58 & 4.59 & 4.61 & 4.59 & 0.03 & & 0.01 \\
\hline $55 / 45.00$ & 5.14 & 5.15 & 5.14 & 5.16 & 5.17 & 5.15 & 5.15 & 0.52 & & 0.03 \\
\hline $50 / 50.00$ & 4.59 & 4.59 & 4.57 & 4.56 & 4.58 & 4.59 & 4.58 & 0.02 & & 0.02 \\
\hline $45 / 55.00$ & 4.56 & 4.54 & 4.56 & 4.55 & 4.54 & 4.58 & 4.56 & 0.02 & & 0.04 \\
\hline $40 / 60.00$ & 4.56 & 4.57 & 4.59 & 4.56 & 4.58 & 4.57 & 4.57 & 0.02 & & 0.03 \\
\hline $35 / 65.00$ & 4.39 & 4.36 & 4.37 & 4.39 & 4.39 & 4.36 & 4.38 & 0.00 & & 0.03 \\
\hline $30 / 70.00$ & 4.44 & 4.47 & 4.47 & 4.5 & 4.47 & 4.47 & 4.47 & 0.00 & & 0.03 \\
\hline $25 / 75.00$ & 4.49 & 4.47 & 4.5 & 4.48 & 4.47 & 4.47 & 4.48 & 0.00 & & 0.03 \\
\hline $20 / 80.00$ & 4.5 & 4.51 & 4.52 & 4.53 & 4.54 & 4.51 & 4.52 & 0.01 & & 0.04 \\
\hline $15 / 85.00$ & 4.52 & 4.51 & 4.52 & 4.53 & 4.52 & 4.53 & 4.52 & 0.01 & & 0.02 \\
\hline $10 / 90.00$ & 4.51 & 4.51 & 4.52 & 4.53 & 4.52 & 4.53 & 4.52 & 0.01 & & 0.02 \\
\hline $5 / 95.00$ & 4.52 & 4.53 & 4.51 & 4.52 & 4.51 & 4.53 & 4.52 & 0.01 & & 0.02 \\
\hline \multirow[t]{5}{*}{$0 / 100.00$} & 4.53 & 4.52 & 4.52 & 4.54 & 4.55 & 4.53 & 4.53 & 0.01 & & 0.03 \\
\hline & & & & & & & 93.08 & 1.23 & & 0.54 \\
\hline & & & & & & $\mathrm{CL}$ & 4.43 & 0.25 & $\mathrm{CL}$ & 0.03 \\
\hline & & & & & & UCL & 5.17 & & UCL & 0.05 \\
\hline & & & & & & LCL & 3.69 & & LCL & 0.01 \\
\hline
\end{tabular}

Table5.9. Micro- Porosity of Pellet (\%)

\begin{tabular}{|l|l|l|l|l|l|l|l|l|l|l|}
\hline BLEND RATIO & 1 & 2 & 3 & 4 & 5 & 6 & Average & $\begin{array}{l}\text { Standrad } \\
\text { Deviation }\end{array}$ & Range \\
\hline $100 / 0.00$ & 7.72 & 7.72 & 7.72 & 7.74 & 7.75 & 7.76 & 7.74 & 1.51 & 0.04 \\
\hline $95 / 5.00$ & 7.75 & 7.74 & 7.75 & 7.78 & 7.78 & 7.75 & 7.76 & 1.45 & 0.04 \\
\hline $90 / 10.00$ & 7.78 & 7.79 & 7.78 & 7.77 & 7.77 & 7.77 & 7.78 & 1.41 & & 0.02 \\
\hline
\end{tabular}


Statistical Quality Control on the Mechanical Properties on Resultant Pellets of Itakpe And Agbaja Iron Ore Blends

\begin{tabular}{|l|l|l|l|l|l|l|l|l|l|l|}
\hline $85 / 15.00$ & 7.95 & 7.98 & 7.95 & 7.94 & 7.94 & 7.96 & 7.95 & 1.02 & 0.02 \\
\hline $80 / 20.00$ & 8.05 & 8.05 & 8.05 & 8.09 & 8.09 & 8.07 & 8.07 & 0.80 & & 0.04 \\
\hline $75 / 25.00$ & 8.26 & 8.27 & 8.25 & 8.28 & 8.28 & 8.29 & 8.27 & 0.48 & & 0.03 \\
\hline $70 / 30.00$ & 8.34 & 8.36 & 8.34 & 8.38 & 8.38 & 8.39 & 8.37 & 0.36 & 0.05 \\
\hline $65 / 35.00$ & 8.55 & 8.59 & 8.55 & 8.56 & 8.56 & 8.55 & 8.56 & 0.16 & 0.04 \\
\hline $60 / 40.00$ & 8.87 & 8.88 & 8.87 & 8.87 & 8.87 & 8.86 & 8.87 & 0.01 & 0.02 \\
\hline $55 / 45.00$ & 9.09 & 9.08 & 9.09 & 9.06 & 9.06 & 9.08 & 9.08 & 0.01 & & 0.03 \\
\hline $50 / 50.00$ & 9.09 & 9.07 & 9.09 & 9.09 & 9.09 & 9.09 & 9.09 & 0.02 & 0.02 \\
\hline $45 / 55.00$ & 9.15 & 9.15 & 9.15 & 9.17 & 9.17 & 9.19 & 9.16 & 0.04 & 0.17 & 0.04 \\
\hline $40 / 60.00$ & 9.38 & 9.36 & 9.36 & 9.38 & 9.38 & 9.38 & 9.37 & 0.17 & 0.02 \\
\hline $35 / 65.00$ & 9.34 & 9.37 & 9.34 & 9.36 & 9.36 & 9.34 & 9.35 & 0.15 & & 0.03 \\
\hline $30 / 70.00$ & 9.45 & 9.48 & 9.45 & 9.49 & 9.49 & 9.46 & 9.47 & 0.26 & & 0.04 \\
\hline $25 / 75.00$ & 9.55 & 9.56 & 9.55 & 9.58 & 9.58 & 9.55 & 9.56 & 0.36 & & 0.03 \\
\hline $20 / 80.00$ & 9.6 & 9.63 & 9.6 & 9.62 & 9.62 & 9.62 & 9.62 & 0.42 & & 0.03 \\
\hline $15 / 85.00$ & 9.67 & 9.69 & 9.67 & 9.64 & 9.64 & 9.65 & 9.66 & 0.49 & & 0.03 \\
\hline $10 / 90.00$ & 9.97 & 9.98 & 9.97 & 9.97 & 9.97 & 9.99 & 9.98 & 1.02 & & 0.02 \\
\hline $5 / 95.00$ & 10.55 & 10.56 & 10.56 & 10.59 & 10.59 & 10.56 & 10.57 & 2.58 & & 0.03 \\
\hline $0 / 100.00$ & 9.97 & 9.99 & 9.96 & 9.98 & 9.97 & 9.97 & 9.97 & 1.02 & & 0.02 \\
\hline & & & & & & & 188.23 & 13.73 & & 0.64 \\
\hline & & & & & & CL & 8.96 & 0.82 & CL & 0.03 \\
\hline & & & & & & UCL & 11.43 & & UCL & 0.05 \\
\hline & & & & & & LCL & 6.49 & & LCL & 0.01 \\
\hline
\end{tabular}

\section{Presentation AND Analysis of DAta}

To attain the aims and objectives of this study, all the data gathered from the mechanical properties of the produced pellets

using the Itakpe and Agbaja iron ore blends were presented and analyzed.

\subsection{Drop Number}

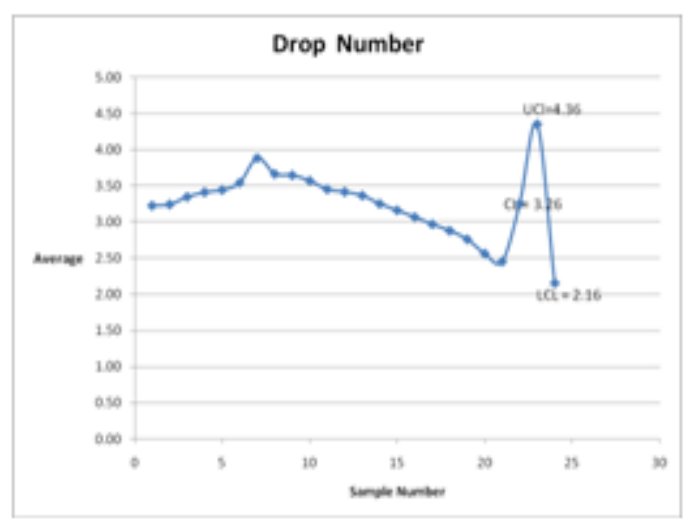

Figure 1(a) shows the average of Drop Number Test @ $60 \mathrm{~cm}$ with the X control chart

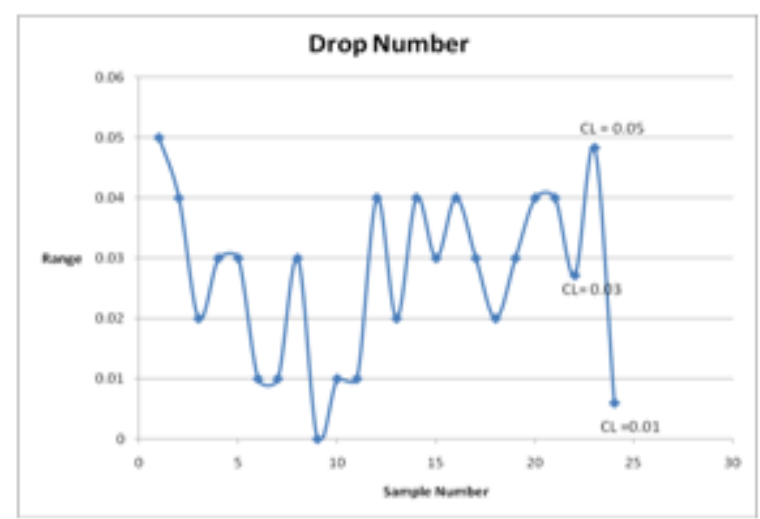

Figure 1(b) shows the range of Drop Number Test @ $60 \mathrm{~cm}$ with the $\mathrm{R}$ control chart

\subsection{Drop Resistance Test @ 48cm, $60 \mathrm{~cm} \& 72 \mathrm{~cm}$}

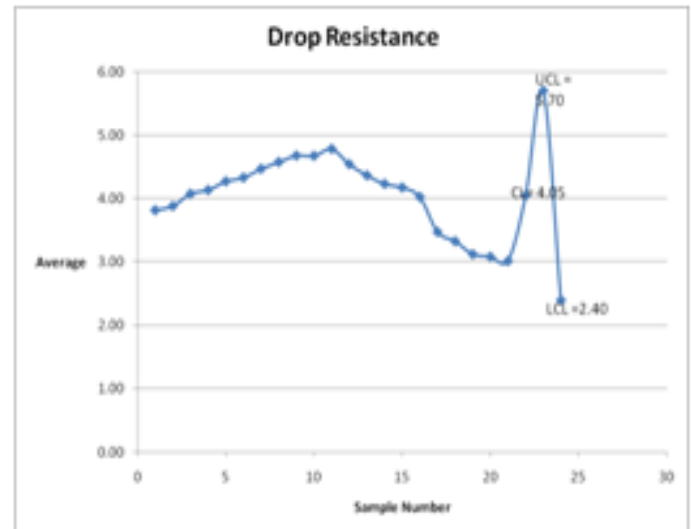

Figure 2(a) shows the average of Drop Resistance Test@48cm, $60 \mathrm{~cm} \& 72 \mathrm{~cm}$ with the X control chart

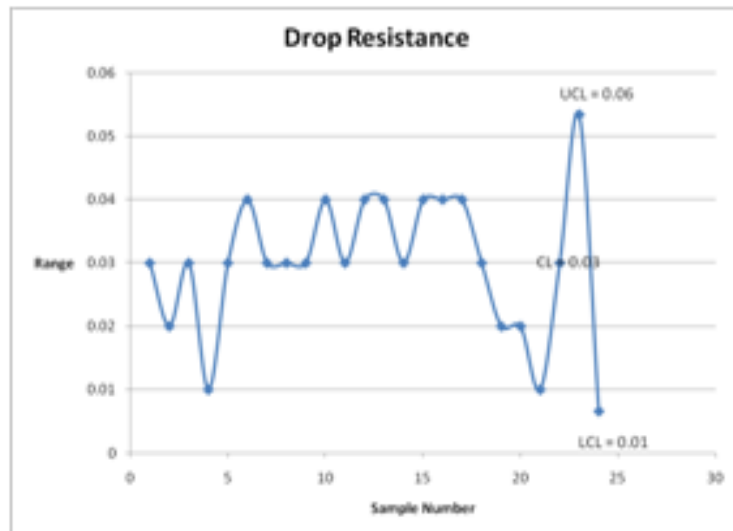

Figure 2(b) shows the range of Drop Resistance Test @ $48 \mathrm{~cm}, 60 \mathrm{~cm} \& 73 \mathrm{~cm}$ with the R control chart 
Statistical Quality Control on the Mechanical Properties on Resultant Pellets of Itakpe And Agbaja Iron Ore Blends

\subsection{Green Compressive Strength Test}

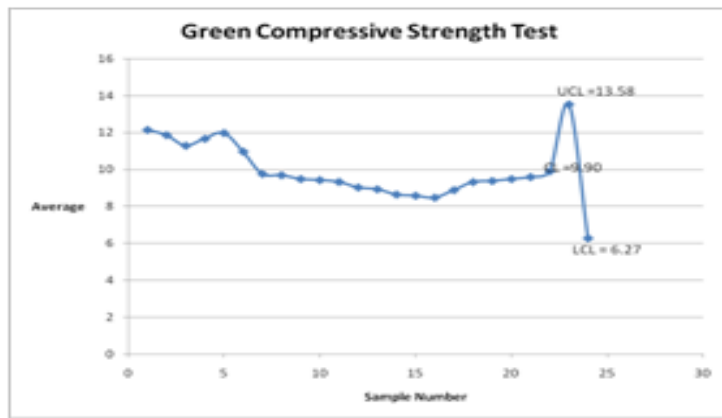

Figure 3(a) shows the average of Green compres sive Strength Test with the $\mathrm{X}$ control chart

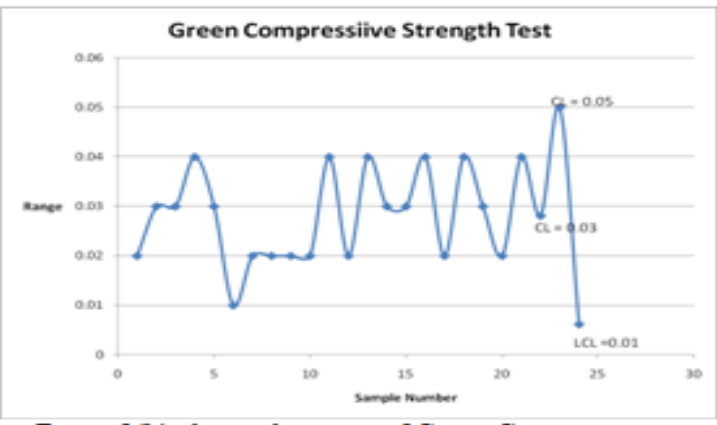

Figure 3(b) shows the range of Green Compressive strength Test with the $R$ control chart

6.4 Dry Compressive Strength Test @6000C. (N/P)

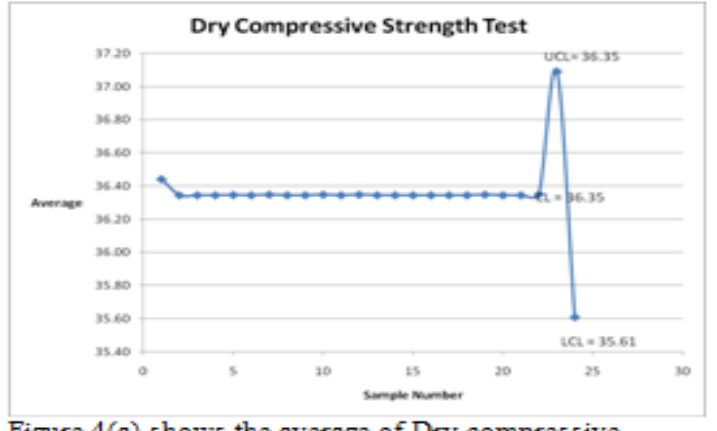

Figure 4 (a) shows the average of Dry compressive Strength Test @600 $\mathrm{C}$. (N/P) with the X control chart

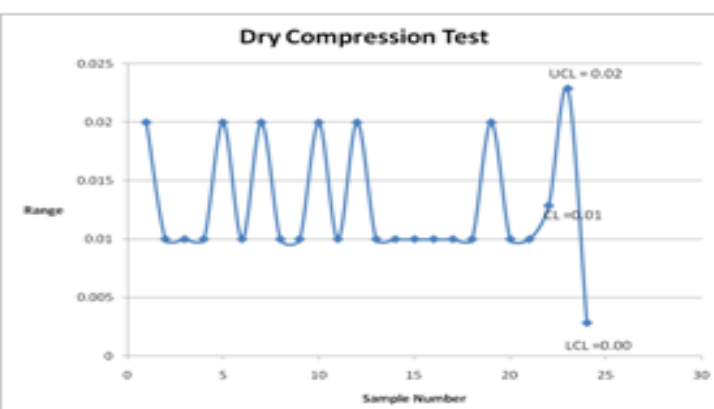

Figure 4 (b) shows the range of Dry Compressive strength Test @600 6 . (N/P) with the R control chart

\subsection{Indurating Compressive Strength Test@ $12000 \mathrm{C}(\mathrm{N} / \mathrm{P})$}

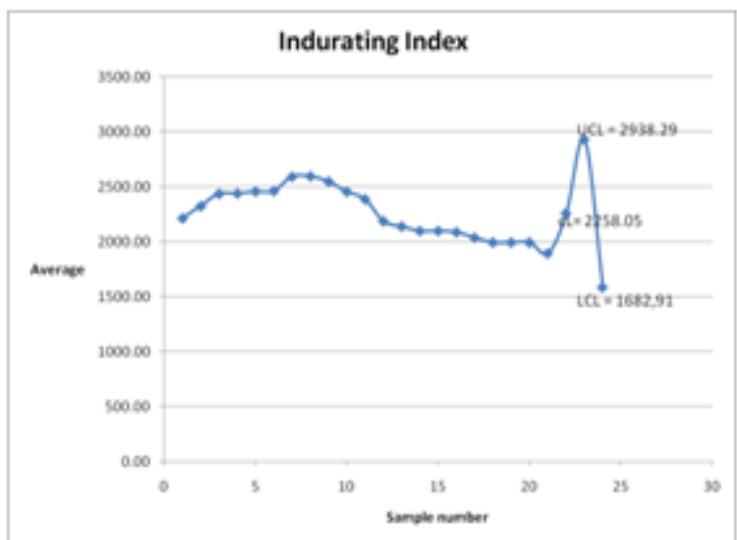

Figure 5(a) shows the average of Indurating Compres sive Strength Test@1200 $\mathrm{C}(\mathrm{N} / \mathrm{P})$ with the X control chart

\subsection{Moisture Content}

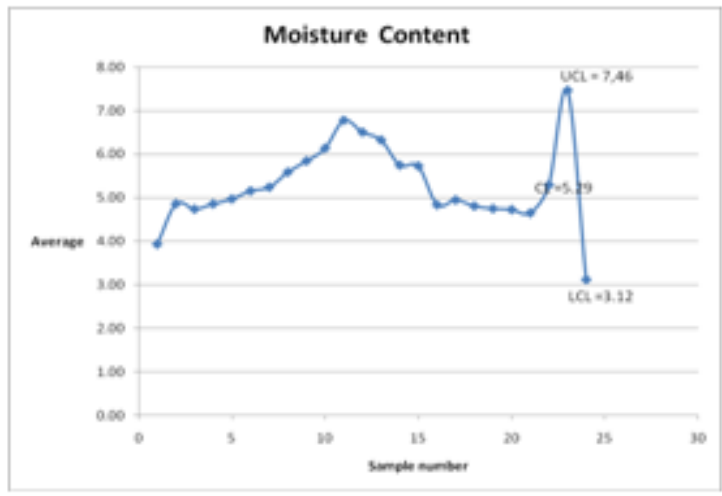

Figure 6(a) shows the average of Moisture Content Per Pellet (ml) with the X control chart

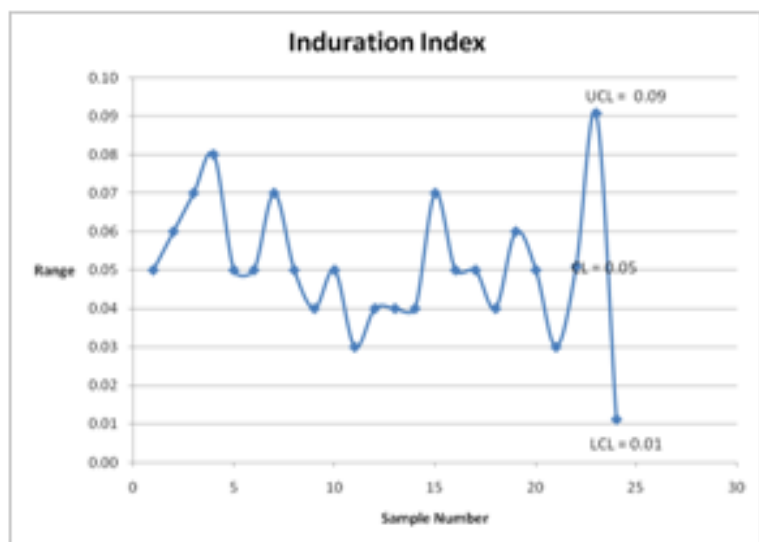

Figure 5(b) shows the range of Indurating Compres sive Strength Test $@ 1200^{\circ} \mathrm{C}(\mathrm{N} / \mathrm{P})$ with the $\mathrm{R}$ control chart

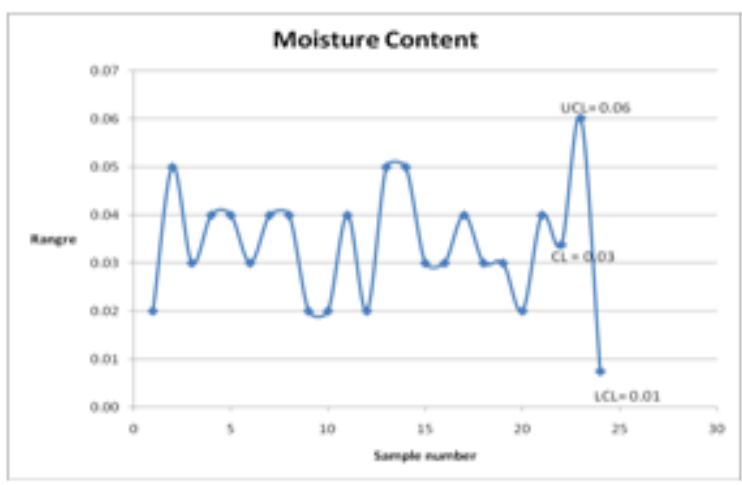

Figure 6(b) shows the range of Moisture Content per Pellet (ml) with the R control chart 


\subsection{Timber Index Test (\%)}

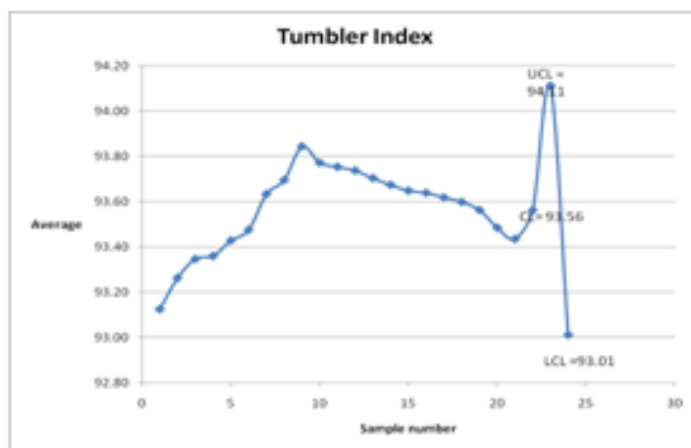

Figure 7(a) shows the average of Timber Index Test (\%) With the $\mathrm{X}$ control chart

\subsection{Abrasion index value (\%)}

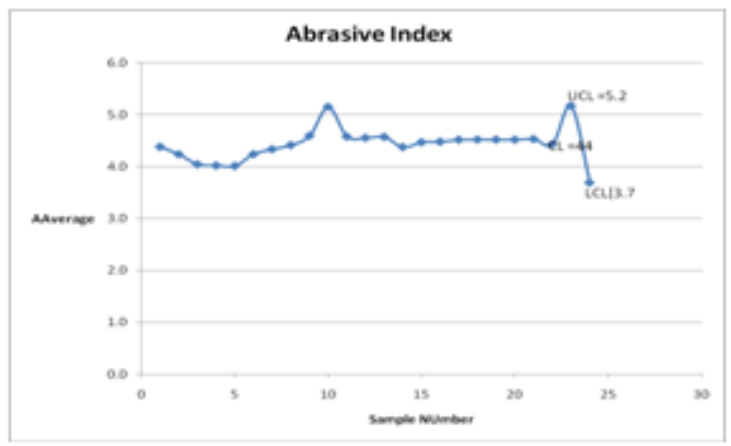

Figure 8(a) shows the average of Abrasive index Test (\%) With the $\mathrm{X}$ control chart

\section{9: Micro- Porosity of Pellet (\%)}

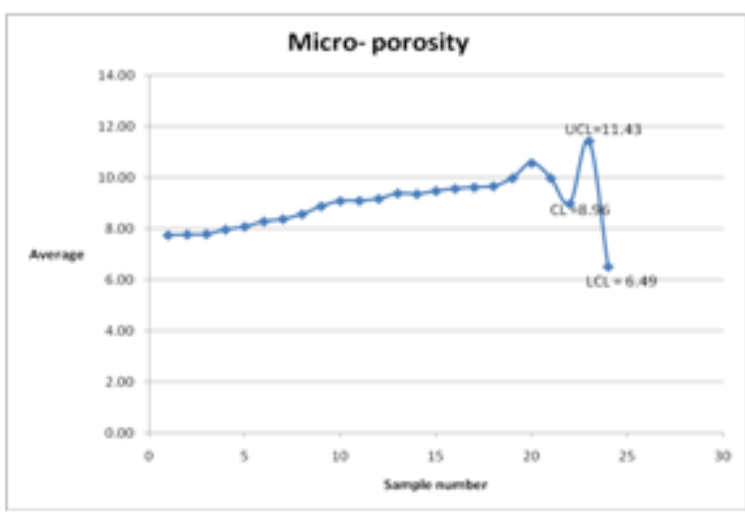

Figure 9(a) shows the average of Micro Porosity of Pellet (\%) with the $\mathrm{X}$ control chart

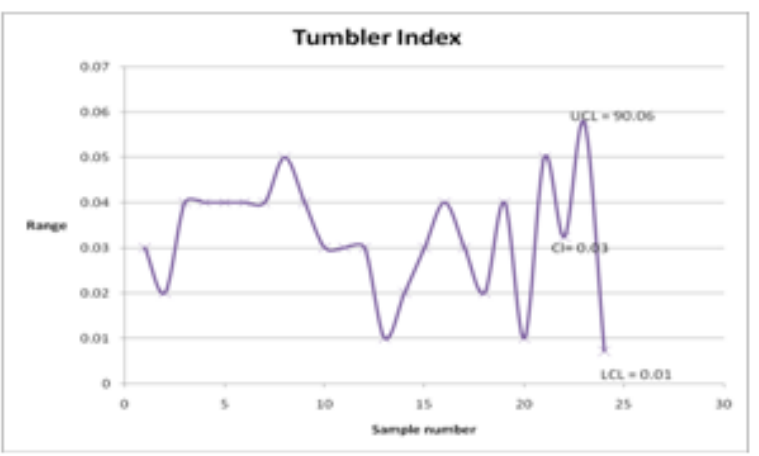

Figure 7(b) shows the range of Timber Index Test (\%) with the $\mathrm{R}$ control chart

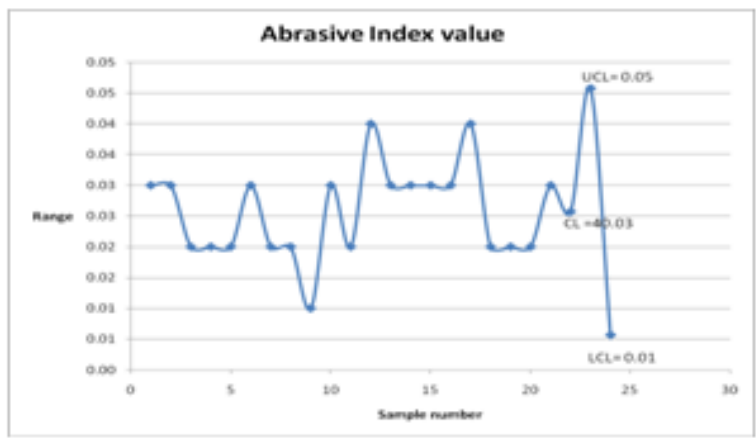

Figure 8(b) shows the range of Abrasive Index Test (\%) with the $R$ control chart

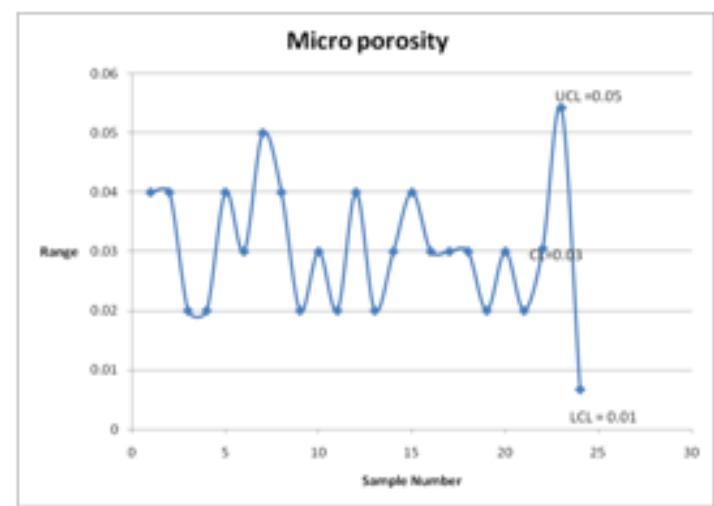

Figure 9 (b) shows the range of Micro Porosity of Pellet (\%) with the $\mathrm{R}$ control chart

\section{RESUltS AND DisCUSSIONS}

\subsection{Interpreting Control Charts for Variables}

The behaviour of the points on the various charts indicate that all the points fell within the upper and lower control limits. With these results it is easy to detect and monitored the vairabilty in the prodcution process. This was achieved by using these two control charts based on control limits, The standard deviation and simple ranges were calculated with the standard formula .

These average values were plotted on the control charts . Also the $\bar{X}$ - Chart and $\overline{\mathbf{R}}$ - Chart were also plotted and the results indicate that the points fell within the limits which translates that there were no sporadic variations that could have caused the processes to be stopped.

The $\bar{X}$ - Chart and $\overline{\mathrm{R}}$ - Chart are control charts that was used in plotting the avearge and ranges of the samples. These Chart are widely used in the industry because they are computationally simple 
and easy to understand. The control limits were calculated using the equation below, along with the appropriate predetermined factors $\mathrm{D}_{3(0.22)}$ and $\mathrm{D}_{4(1.78)}$ given in Table (Factors $\mathrm{A}_{2}, \mathrm{D}_{3}$ and $\mathrm{D}_{4}$ for $\bar{X}-$ Chart and $\overline{\mathrm{R}}$ - Chart for three - Standard - devaition control limits),[10].

From all the results we observed that all the points plotted fell within the Upper and Lower control limits. The results implied that the produced pellets were all within the standard range. The process should therefore be allowed to continue and more efforts was required to sustain the trend and the behaviour of the production process.

\section{CONCLUSION}

It is note worthly to conclude that the use of statistical quality control process had assisted the reserachers to monitor and control the production process in determining the mechnical propoerties of the pellets produced from the Itakpe and Agbaja iron ore blends . the results obtained indicate that all the values fell within the process control in the the charts. The results also showed that all the points are within the Upper Control Limit and Lower Control Limit and in such cases the production processes are allowed to continue by monitirong and closely observing the production processes for sustainability.

The process further assisted in monitoring and eliminating bad products, rejects scraps and thus reduced wastes that could have had caused problems on the production of the pellets. The quality of the products and the production processes were confirmed to have met global and international standards, which indicated that the products were able to meet the requirments, specifications and satisfaction of the customer by meeting the internationally accepted standards.

The process indicated that the produced pellets will be able to perform satisfactorily in the application for which they were intended for by the user, the performance of the products did not exhibit deleterious effect on it applications.

That the project was successfully completed and the data generated should serve as data

bank which could further translate to generating valid information for further study on similar or other iron ores that are available in the country. That the relevant data could assist the would be researchers in this field which has created ample opportunity of the needed knowledge on the best methods and necessary studies on mechanical properties of blend ores with a view to blending them for making pellets that could be use as burden materials in the operation of the Blast furnace and the production of steel through the Direct Reduced Iron (DRI).

Finally, the use of the statistical quailty control had assisted in detecting and eliminating non-random (Sporadic) variation in the production process and had also being used to determine the mechanical properties of the pellets with zero defect, which mean that the products are defect free through prevention .

\section{REFERENCES}

[1] Adeleye R.A., "The occurrence of Oolitic iron ore in the Middle Niger Basin in Geology of Nigeria". Kogbe, C.A. Edition Elizabeth press, Lagos: 1964 pp 1-10.

[2] BRG report. "Survey, Research and test of Agbaja, Lokoja, Koton -Karfe and Bassange iron ore deposits, final report".1983

[3] Adedeji F.A. \& Sale F.R. "Characterization and Reducibility of Itakpe and Agbaja (Nigerian) Iron ores" . Delta Steel Complex Warri, Nigeria and Department of Metallurgy and Materials Science, University of Manchester Grosvenor Street, Manchester M! 7HS”1984, 843-856

[4] Mohammed R.A., Dada E.T, Hassan S.B., Abdulwahab M “Assessment of Mechanical Properties of Pellets Produced From Itakpe/Agbaja Iron Ore Blends" A paper published in the Nigerian Metallurgical Proceeding at the $30^{\text {th }}$ Annual Conference and Annual General Meeting of the Nigerian Metallurgical Society at the Raw Materials Research and Development Council Abuja .2014 paper 14

[5] Jain K.C. and Chitale A.K "Quality Assurance and Total Quality Management" 3ed.,Khanna Publishers,Delhi-110006, 2003 pp.418-421.

[6] Lucey“Quantitaive Techniques”,6ed.,ELBS, Geat Britain , 2000 pp117-120 
[7] Grant, E.L.and R.S. Leavenworth , "Statistical Quality Control”, 6ed. New YORK : McGraw- Hill1988

[8] Deming, W. Edwards “On Some Statistical Aids Toward Economic production," Interfence, no5 1959 pp115

[9] Saniga, Erwin M., and Larry E. Shirland, "Quality Control in Practice...A Survey" Quality Process 10, no. 51977 pp30-33

[10] Everette.Adam, Jr. Ronald J. Ebert "Production and Operations Management -Concepts, Models, and Behaviour",5ed.,Prentice -Hall of India private Limited, New Delhi-110001, 2003 PP.634-648.

Citation: Ocheri C, et.al., (2020). "Statistical Quality Control on the Mechanical Properties on Resultant Pellets of Itakpe And Agbaja Iron Ore Blends". ", International Journal of Modern Studies in Mechanical Engineering (IJMSME), 6(2), pp. 1-15. DOI: http://dx.doi.org/10.20431/2454-9711.0602001

Copyright: () 2020Authors. This is an open-access article distributed under the terms of the Creative Commons Attribution License, which permits unrestricted use, distribution, and reproduction in any medium, provided the original author and source are credited. 